\title{
Real-world comparison of the effectiveness and safety of different bowel preparation agents
}

This article was published in the following Dove Press journal: Clinical and Experimental Gastroenterology

\author{
Naomi C Sacks ${ }^{1,2}$ \\ Abhishek Sharma' \\ Philip L Cyr ${ }^{1,3}$ \\ Gerald Bertiger ${ }^{4}$ \\ David N Dahdal ${ }^{5}$ \\ Stuart P Brogadir ${ }^{5}$ \\ 'Precision Xtract, Boston, MA, USA; \\ ${ }^{2}$ Public Health and Community \\ Medicine, Tufts University School of \\ Medicine, Boston, MA, USA; ${ }^{3}$ College \\ of Health and Human Services, \\ University of North Carolina, \\ Charlotte, NC, USA; ${ }^{4}$ Hillmont \\ GI, Flourtown, PA, USA; ${ }^{5}$ Ferring \\ Pharmaceuticals Inc., Parsippany, NJ, \\ USA
}

Background and aims: Proper bowel cleansing is necessary prior to colonoscopy, but poor tolerability to bowel preparation agents may increase the odds of poor cleansing and incomplete screenings. The aim of this study was to evaluate the real-world effectiveness and safety of bowel preparation agents.

Methods: Claims data were extracted for individuals who had a screening colonoscopy from July 1,2012 , to June 30,2015 , were $\geq 18$ years of age, and who could be observed $\geq 6$ months before and $\geq 3$ months after the screening. Data were stratified by agent class, including overthe-counter (OTC), low-volume (LV), and high-volume (HV) agents. Rates of incomplete screenings, repeat screenings, and hospitalizations were reported. Multivariate logistic regression was conducted to compare outcomes for sodium picosulfate, magnesium oxide, and citric acid (P/MC) vs other agents.

Results: Of 2.8 million individuals, $71.5 \%$ were average risk and $28.5 \%$ were high risk for colorectal cancer. Rates of use were $2.8 \%$ for P/MC, $30.1 \%$ for other $\mathrm{LV}$ agents, $9.4 \%$ for $\mathrm{HV}$ agents, and 56.6\% for OTC agents. All individuals who used $\mathrm{P} / \mathrm{MC}$ had significantly lower odds of incomplete screenings compared to those who used other LV agents or HV agents $(P<0.05)$. In average-risk patients, rates of 30- and 90-day repeat screenings were highest for the $\mathrm{P} / \mathrm{MC}$ group ( $16.7 \%$ and $23.0 \%$, respectively) compared to other agents. Across all patient analysis groups, the rates of hospitalizations for hyponatremia or dehydration were much higher for those who used an OTC bowel preparation agent compared to those who used LV or $\mathrm{HV}$ agents, or $\mathrm{P} / \mathrm{MC}$.

Conclusion: $\mathrm{P} / \mathrm{MC}$ was associated with lower rates of incomplete colonoscopy and higher rates of repeat screenings, suggesting it was better tolerated than other agents. OTC agents were associated with higher rates of hospitalizations.

Keywords: colonoscopy, colorectal cancer screening, bowel purgative, bowel preparation, incomplete colonoscopy

\section{Introduction}

Colorectal cancer (CRC) screening is recommended for prevention and early detection of CRC. ${ }^{1,2}$ Individuals with no personal or family history of CRC or polyps are advised to undergo screening every 10 years, while those who are at higher risk (those with a personal/family history of colorectal disease, including those with inflammatory bowel disease $[\mathrm{IBD}])$ should be screened more often. ${ }^{3}$

Colonoscopy is the most common method for CRC screening in the United States (US) and is associated with a decreased incidence of CRC and death due to CRC. ${ }^{4-6}$ Proper bowel cleansing is necessary to achieve a successful colonoscopy. ${ }^{7-10}$
Correspondence: Stuart P Brogadir Ferring Pharmaceuticals Inc., 100 Interpace Pkwy, Parsippany, NJ 07054, USA

Tel + I 9732064444

Email Stuart.Brogadir@ferring.com 
Unfortunately, bowel preparation is widely viewed by patients as a significant negative aspect of the colonoscopy procedure. ${ }^{11-13}$ Poor tolerability for bowel preparation agents may increase the odds of a patient not taking the full dose, which can lead to poor bowel preparation that prevents screening. A survey of patients undergoing colonoscopy found that poor tolerability to bowel preparation agents was associated with a lower quality screen and fewer polyps detected. ${ }^{14}$ A meta-analysis of bowel preparation agents administered as a split dose showed that their use significantly increased the adequacy of bowel preparations, compared to day-before dosing, and that patients taking a split dose had significantly higher willingness to repeat preparation with the same agent; similar results were seen for same-day dosing. ${ }^{15,16}$

An earlier claims study examined the hospitalizations and need for repeat screenings among patients using commonly prescribed prescription bowel preparation agents. ${ }^{17}$ However, that study did not include over-the-counter (OTC) preparation agents, which account for a significant portion of the bowel preparation agents used for screening colonoscopies. ${ }^{18}$ The study also did not assess the rate of incomplete screening colonoscopies or data from high-risk individuals, thus giving only a partial view of the real-world effectiveness and safety of bowel preparation agents.

The aim of the current study was to evaluate the realworld effectiveness and safety of bowel preparation agents by measuring rates of incomplete screenings, repeat screenings, and hospitalizations after screenings, stratified by bowel preparation agent, including in high-risk individuals.

\section{Methods}

\section{Study design}

This was a retrospective cohort study of outcomes of screening colonoscopy in individuals using different bowel preparation agents, identified in employer-based health insurance claims. De-identified data, licensed from the Truven Health Analytics Commercial and Medicare Supplemental MarketScan databases (Truven Health Analytics, Ann Arbor, MI, USA), were extracted for the period from July 1, 2012, through June 30, 2015. This study was exempt from IRB approval as it did not involve any biomedical research with human subjects.

The index screening was defined as the first screening colonoscopy identified for the individual during the study period. Screening colonoscopies were identified based on ICD, ninth revision, Clinical Modification (ICD-9-CM) procedure codes: 4522, 4524, 4523, 44355, 44388-44394, 45378-45387, 45391, 45392, G0105, G0121, G0104, G0106, or G0120. Screening colonoscopies identified by these codes were also included if they had a modifier code of 33 or PT, indicating one or multiple polyp(s) were removed. High-risk individuals were identified by a screening procedure code of V1005, V1006, V1272, V160, V1851, V7641, V7651, V8409, or G0105. All other colonoscopies were considered to be diagnostic, rather than screening, procedures and were not included in the study.

Data from screening colonoscopies using sodium picosulfate, magnesium oxide, and citric acid (P/MC) low-volume bowel preparation agents were compared to 1) all other lowvolume (LV) agents as a class, 2) the two most commonly prescribed LV agents (oral sulfate solution [OSS]; polyethylene glycol plus ascorbic acid [PEG + AA]), 3) high-volume (HV) agents, and 4) OTC agents.

$\mathrm{LV}$ agents were defined as those with $<4 \mathrm{~L}$ solution; HV agents were those with $\geq 4 \mathrm{~L}$ solution (based on their approved labeling and directions for use). ${ }^{19,20}$ Tablet-based agents were categorized as "other bowel preparation agents." In the US, OTC medicines are not covered by health insurance and will not show up in administrative claims databases. Therefore, the lack of a prescription filled in the claims database for a bowel preparation agent within 90 days before the screening was used to identify individuals assumed to have used an OTC preparation agent.

\section{Study population}

Individuals were included in the study if they had at least one colonoscopy during the study period, were $\geq 18$ years of age at the time of the index screening, and could be observed for at least 6 months before and at least 3 months after the index screening in the database.

Individuals were stratified by the presence or absence of risk factors for CRC into those who were considered to have average risk (no personal/family history) and those who were deemed high-risk (with a personal/family history of colorectal disease). A subset of individuals in the highrisk group with IBD was analyzed separately. Individuals with IBD were identified by ICD-9-CM diagnosis codes for ulcerative colitis: 560.89, 556.0, 556.1, 556.2, 556.3, 556.4, 556.5, 556.6, 556.8, or 556.9; or Crohn's disease: 555.0, $555.1,555.2$, or 555.9 .

De-identified data were extracted for each individual: age; sex; health status (measured by the Charlson comorbidity index [CCI]); comorbidities (diabetes, heart disease, cerebrovascular disease, renal disease, liver disease, prior cancer); and prescription medication use. The $\mathrm{CCI}$ is widely used as a measure of a person's health status that summarizes comorbidities for each individual on the basis of diagnosis 
codes found in administrative claims data, with higher scores indicative of poorer health..$^{21,22}$

\section{Outcomes}

The effectiveness outcomes examined in this study were the number of incomplete screenings, and the number of return screenings following an incomplete screening. Incomplete screenings were defined as screening colonoscopies with a procedure modifier code of $22,52,53,73$, or 74 . A repeat screening was defined as a second screening colonoscopy that occurred within 30 days or 90 days of the index screening. A second screening colonoscopy that occurred within 90 days of an incomplete screening indicated a return due to the failure of the index screening, as the guideline-recommended regular screening interval is at least 1 year or longer. ${ }^{1-3,23}$

Adverse events included in this study were hospitalizations due to hyponatremia (identified by ICD-9-CM diagnosis code 276.1 or 276.0 ) or to dehydration (identified by ICD-9-CM diagnosis code 276.50, 276.51, or 276.52) that occurred within 10 days of the index screening. Fluid levels in an individual following a bowel preparation are a particular concern for those using LV agents, and these hospitalizations would likely indicate an issue with product safety that could have been associated with the preparation agent.

\section{Statistical analysis}

Descriptive statistics (mean, SD, range) were calculated for the demographic and clinical characteristics in each cohort. Rates of incomplete screenings, repeat screenings, and hospitalizations due to adverse events were calculated. The rate of repeat screenings was calculated as a proportion of the number of incomplete screenings.

Multivariate logistic regression, adjusting for age, sex, illness burden (CCI), comorbidities, and medication use, was conducted to evaluate whether the outcomes were significantly different for individuals who received $\mathrm{P} / \mathrm{MC}$ compared to $\mathrm{HV}$ agents, $\mathrm{P} / \mathrm{MC}$ compared to other LV agents, $\mathrm{P} / \mathrm{MC}$ compared to OTC agents, and $\mathrm{P} / \mathrm{MC}$ compared to OSS or PEG + AA. In all comparisons, the LV class data did not include $\mathrm{P} / \mathrm{MC}$. Point estimates were examined for age and sex covariates to determine the effect, if any, of these variables on the rates of incomplete and repeat screenings.

All analyses were conducted using SAS Version 9.4.

\section{Results}

\section{Demographic characteristics}

A total of 2.8 million individuals were included in the study (Table 1). Most individuals (71.5\%) were categorized as having average risk for $\mathrm{CRC}$, while $28.5 \%$ were high risk. Of the high-risk group, $4.5 \%$ had IBD and $24.0 \%$ had a non-IBD personal history of colorectal disease or any family history of colorectal disease.

In the average-risk group $(n=2,013,880), 54.7 \%$ were female, the mean (SD) age was 55.8 (11.1) years, and the mean (SD) CCI score was 0.47 (1.04) (Table 1). In this group, $56.5 \%$ used an OTC preparation agent, 30.2\% used a LV agent, and 9.5\% used a HV agent (Table 1).

The high-risk group and the IBD subgroup had similar demographic characteristics and patterns of use for the classes of bowel preparation agents (Table 1).

\section{Average-risk group}

\section{Incomplete screenings}

The rates of incomplete screening colonoscopies were $0.93 \%$ among individuals who used LV agents, $0.92 \%$ with HV agents, and $0.79 \%$ with OTC agents (Table 2). For the three most frequently used LV agents, the rates of incomplete screenings were $0.76 \%$ for $\mathrm{P} / \mathrm{MC}, 0.88 \%$ for OSS, and $1.01 \%$ for PEG + AA. In multivariate analyses that controlled for age, sex, illness burden, comorbidities, and medication use, individuals who used $\mathrm{P} / \mathrm{MC}$ had significantly lower odds of incomplete screenings compared to other LV agents as a class $(P<0.0001)$, HV agents $(P<0.01)$, OSS $(P<0.01)$, or PEG + AA $(P<0.0001)$ (Table 2$)$. There was no significant difference in the odds of an incomplete screening between individuals who used $\mathrm{P} / \mathrm{MC}$ or OTC bowel preparation agents.

Among average-risk patients, women were 1.4-1.5 times more likely to have an incomplete screen, compared to men $(P<0.0001$; Table $\mathrm{S} 1)$. Age did not have a significant effect on the odds of an incomplete screen, except in the cohort comparison of $\mathrm{P} / \mathrm{MC}$ with OTC, where the odds of an incomplete screen was $1.004(P=0.0378)$ with each additional year of age.

\section{Repeat screenings}

Of the individuals who had an incomplete screening, the rates of 30- and 90-day repeat screenings were highest for those using $\mathrm{P} / \mathrm{MC}$ (16.7\% and $23.0 \%$, respectively; Table 2). Results of multivariate analyses showed that individuals who used P/MC had 1.9 times the odds of returning for a repeat screening as individuals who used other LV agents $(P<0.0001), 1.5$ times the odds as those who used an HV agent $(P<0.01), 2.6$ times the odds of returning as those who used OSS $(P<0.0001)$, and 1.5 times the odds as those who used $\mathrm{PEG}+\mathrm{AA}(P<0.01)($ Table 2$)$. There was no significant difference between individuals who used $\mathrm{P} / \mathrm{MC}$ or OTC bowel 
Table I Demographic characteristics, by risk group and agent class

\begin{tabular}{|c|c|c|c|c|}
\hline Group & Individuals, n (\%) & Age, years, mean (SD) & Female, \% & $\mathrm{CCl}$, mean (SD) \\
\hline Average risk & $2,013,880(7 \mid .5)$ & $55.8(11.1)$ & 54.7 & $0.47(1.04)$ \\
\hline $\mathrm{P} / \mathrm{MC}$ & $54,580(2.7)$ & $54.0(10.1)$ & 59.2 & $0.33(0.84)$ \\
\hline$L^{a}$ & $607,692(30.2)$ & $55.0(10.3)$ & 54.6 & $0.36(0.89)$ \\
\hline HV & |9|,304 (9.5) & $56.9(10.8)$ & 52.8 & $0.44(0.99)$ \\
\hline Other agents & $22,494(1.1)$ & $54.7(10.0)$ & 65.1 & $0.33(0.83)$ \\
\hline Отс & $\mathrm{I}, 137,810(56.5)$ & $56.2(11.5)$ & 54.6 & $0.53(1.12)$ \\
\hline High risk & $804,263(28.5)$ & $57.0(11.2)$ & 53.0 & $0.46(1.02)$ \\
\hline $\mathrm{P} / \mathrm{MC}$ & $23,518(2.9)$ & $55.3(10.4)$ & 58.7 & $0.35(0.88)$ \\
\hline$L^{a}$ & $240,749(29.9)$ & $56.4(10.6)$ & 52.7 & $0.38(0.90)$ \\
\hline HV & $72,638(9.0)$ & $58.6(10.9)$ & 49.7 & $0.43(0.98)$ \\
\hline Other agents & $11,378(1.4)$ & $54.3(10.9)$ & 64.5 & $0.33(0.89)$ \\
\hline Отс & $455,980(56.7)$ & $57.5(11.6)$ & 53.1 & $0.5 \mathrm{I}(1.08)$ \\
\hline IBD & $|25,98|(4.5)$ & $50.0(15.5)$ & 55.7 & $0.51(1.13)$ \\
\hline $\mathrm{P} / \mathrm{MC}$ & $3,630(2.9)$ & $48.1(14.0)$ & 62.0 & $0.34(0.88)$ \\
\hline$L^{a}$ & $35,879(28.5)$ & $49.5(14.3)$ & 55.0 & $0.39(0.94)$ \\
\hline HV & 9,980 (7.9) & $52.4(15.2)$ & 51.6 & $0.48(1.08)$ \\
\hline Other agents & $2,276(1.8)$ & 46.9 (13.9) & 67.4 & $0.31(0.84)$ \\
\hline отс & $74,216(58.9)$ & $50.1(16.2)$ & 55.9 & $0.58(1.23)$ \\
\hline Total & $2,818,143$ & - & - & - \\
\hline All LV & $848,44 I(30.1)$ & - & - & - \\
\hline $\mathrm{P} / \mathrm{MC}$ & $78,098(2.8)$ & - & - & - \\
\hline HV & $263,942(9.4)$ & - & - & - \\
\hline Отс & $\mathrm{I}, 593,790(56.6)$ & - & - & - \\
\hline Other agents & $33,87 \mid(1.2)$ & - & - & - \\
\hline
\end{tabular}

Note: a Data for the LV class do not include P/MC.

Abbreviations: $\mathrm{CCl}$, Charlson comorbidity index; HV, high volume; IBD, inflammatory bowel disease; LV, low volume; OTC, over-the-counter; P/MC, sodium picosulfate, magnesium oxide, and citric acid.

preparation agents in the odds of repeat screening following an incomplete screen.

Female sex was significantly associated with lower odds of returning for a repeat screen in patients who used an OTC agent or P/MC (OR: 0.788; 95\% CI [0.697, 0.89]; $P=0.0001$; Table S1). Each additional year of age was associated with slightly lower odds of returning for a repeat screen in all cohorts $(\mathrm{OR}=0.99 ; P<0.05)$ except for $\mathrm{P} / \mathrm{MC}$ vs OSS.

\section{Hospitalizations}

The rates of hospitalizations within 10 days of the index event due to hyponatremia or dehydration were low $(<0.1 \%)$ across all classes. However, the rates of hospitalizations were much higher for individuals who used an OTC bowel preparation agent than those who used either LV or HV agents or P/MC (Table 3 ). There were no significant differences in the odds of hyponatremia between individuals using P/MC or other agents or agent classes, likely because of the very small number of adverse events recorded. ORs for hospitalizations due to dehydration were not calculated because there were no events reported in individuals using $\mathrm{P} / \mathrm{MC}$.

\section{High-risk group} Incomplete screenings

In high-risk individuals, the rates of incomplete screenings were $0.81 \%$ for $\mathrm{P} / \mathrm{MC}, 1.02 \%$ for OSS, and $1.20 \%$ for $\mathrm{PEG}+\mathrm{AA}$ (Table 4). In multivariate analyses, individuals who used $\mathrm{P} / \mathrm{MC}$ had significantly lower odds of incomplete screenings compared to those using other LV agents as a class $(P<0.0001), \mathrm{HV}$ agents $(P<0.05)$, OSS $(P<0.0001)$, or PEG + AA $(P<0.0001)$. There was no significant difference in the odds of an incomplete screening between individuals using $\mathrm{P} / \mathrm{MC}$ or OTC bowel preparation agents (Table 4).

Among high-risk patients, women in all cohorts were 1.4-1.5 times more likely to have an incomplete screen, compared to men $(P<0.0001$; Table S2). In the $\mathrm{P} / \mathrm{MC}$ vs OTC cohort, each additional year of age was associated with lower odds of an incomplete screening (OR: 0.994; 95\% CI [0.991, 0.997]; $P<0.0001)$.

\section{Repeat screenings}

Of the high-risk individuals who had an incomplete screening, the rates of 30- and 90-day repeat screenings were highest for those using $\mathrm{P} / \mathrm{MC}$ (18.3\% and $23.0 \%$, respectively; 
Table 2 Effectiveness outcomes for average-risk individuals, by agent class and the three most frequently used LV agents

\begin{tabular}{|c|c|c|c|c|c|c|}
\hline Agent & $\begin{array}{l}\text { Index } \\
\text { screenings }^{a} \\
\text { n (\%) }\end{array}$ & $\begin{array}{l}\text { Incomplete } \\
\text { screenings } \\
\% \text { (n) }\end{array}$ & $\begin{array}{l}\text { P/MC odds of } \\
\text { incomplete vs } \\
\text { other agent } \\
(95 \% \mathrm{Cl})\end{array}$ & $\begin{array}{l}\text { 30-day } \\
\text { repeat } \\
\text { screening } \\
\%^{\mathrm{b}}(\mathrm{n})\end{array}$ & $\begin{array}{l}\text { 90-day } \\
\text { repeat } \\
\text { screening } \\
\%(n)\end{array}$ & $\begin{array}{l}\text { P/MC odds } \\
\text { of repeat vs } \\
\text { other agent } \\
(95 \% \mathrm{Cl})\end{array}$ \\
\hline $\mathbf{L V}^{\mathbf{c}}$ & $607,692(30.2)$ & $0.93(5650)$ & $0.8 \mathrm{I}(0.73,0.89)^{\mathrm{d}}$ & $9.4(529)$ & I4.I (794) & $1.9(1.4,2.5)^{d}$ \\
\hline HV & $191,304(9.5)$ & $0.92(1765)$ & $0.84(0.75,0.93)^{\mathrm{e}}$ & $11.8(208)$ & $17.1(301)$ & $1.5(1.1,2.0)^{\mathrm{e}}$ \\
\hline Отс & $\mathrm{I}, 137,810(56.5)$ & $0.79(8943)$ & $1.04(0.94,1.15)$ & $14.7(13 \mid 2)$ & $20.5(1830)$ & I.3 $(0.95,1.7)$ \\
\hline P/MC (LV) & $54,580(2.7)$ & $0.76(4 \mid 3)$ & - & $16.7(69)$ & $23.0(95)$ & - \\
\hline OSS (LV) & $337,754(16.8)$ & $0.88(2969)$ & $0.85(0.77,0.94)^{\mathrm{e}}$ & $7.1(210)$ & $10.9(324)$ & $2.6(1.9,3.5)^{d}$ \\
\hline PEG+ AA (LV) & $242,826(12.1)$ & I.0I (2458) & $0.74(0.67,0.82)^{d}$ & II.6 (286) & $17.2(423)$ & $\mathrm{I} .5(\mathrm{I} . \mathrm{I}, 2.0)^{\mathrm{e}}$ \\
\hline
\end{tabular}

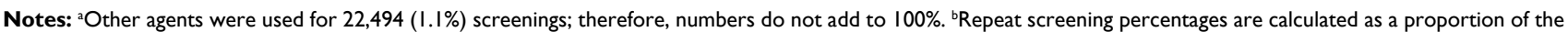
number of incomplete screenings. ' $D$ ata for the LV class do not include $P / M C$. ${ }^{d} P<0.000$ I, compared to $P / M C$. e $P<0.01$, compared to $P / M C$.

Abbreviations: AA, ascorbic acid; HV, high volume; LV, low volume; OSS, oral sulfate solution; OTC, over-the-counter; PEG, polyethylene glycol; P/MC, sodium picosulfate, magnesium oxide, and citric acid.

Table 3 Rates of hospitalizations in average-risk individuals, by agent class and the three most frequently used LV agents

\begin{tabular}{llll}
\hline Agent & $\begin{array}{l}\text { Index } \\
\text { screenings, } \\
\mathbf{N}\end{array}$ & $\begin{array}{l}\text { Hyponatremia } \\
\text { hospitalization } \\
\%(\mathbf{n})\end{array}$ & $\begin{array}{l}\text { Dehydration } \\
\text { hospitalization } \\
\%(\mathbf{n})\end{array}$ \\
\hline LV $^{\mathbf{a}}$ & 607,692 & $0.002(10)$ & $0.00 \mathrm{I}(7)$ \\
HV & 191,304 & $0.001(1)$ & 0 \\
OTC & $1,137,810$ & $0.005(61)$ & $0.015(174)$ \\
P/MC (LV) & 54,580 & $0.002(1)$ & 0 \\
OSS (LV) & 337,754 & $0.001(3)$ & $0.002(6)$ \\
PEG+ AA (LV) & 242,826 & $0.001(2)$ & $0.001(2)$ \\
\hline
\end{tabular}

Note: a aata for the LV class do not include P/MC.

Abbreviations: $A A$, ascorbic acid; HV, high volume; LV, low volume; OSS, oral sulfate solution; OTC, over-the-counter; PEG, polyethylene glycol; P/MC, sodium picosulfate, magnesium oxide, and citric acid.

Table 4). Multivariate analyses showed that individuals who used $\mathrm{P} / \mathrm{MC}$ had 2.6 times the odds of returning for a repeat screening as individuals who used OSS $(P<0.0001)$ and 1.9 times the odds as individuals who used PEG $+\mathrm{AA}(P<0.01)$. When comparing $\mathrm{P} / \mathrm{MC}$ to the classes of bowel preparation agents, individuals who used $\mathrm{P} / \mathrm{MC}$ had $2.0(P<0.01), 2.1$ $(P<0.01)$, and $1.6(P<0.05)$ times the odds of returning for a repeat screening within 90 days of the index screening as individuals using LV, HV, or OTC bowel preparation agents, respectively (Table 4).

There were no significant differences between men and women in the odds of returning for a repeat screening (Table S2). Age was significantly associated with lower odds of a repeat screening for the $\mathrm{P} / \mathrm{MC}$ vs $\mathrm{HV}$ cohort (OR: 0.973, $95 \%$ CI $[0.953,0.994] ; P=0.0122)$.

\section{Hospitalizations}

Similar patterns were seen in the high-risk group as in the average risk group for hospitalizations due to hyponatremia and dehydration (Table 5). Rates of hospitalizations were low and comparable across $\mathrm{P} / \mathrm{MC}$, OSS, and PEG + AA groups, while rates of hospitalizations were higher for the OTC group.

\section{IBD subgroup}

\section{Incomplete screenings}

For high-risk individuals with IBD, the rates of incomplete screening colonoscopies were $0.74 \%$ for $\mathrm{P} / \mathrm{MC}, 1.32 \%$ for OSS, and $1.43 \%$ for PEG + AA (Table 6). In multivariate analyses, individuals who used $\mathrm{P} / \mathrm{MC}$ had significantly lower odds of incomplete screenings compared to other LV agents as a class, to HV agents, OTC agents, and compared to OSS and PEG + AA (all $P<0.01$; Table 6). Individuals with IBD who used $\mathrm{P} / \mathrm{MC}$ had approximately half the odds of an incomplete screening compared to all classes and agents.

Among patients with IBD, women were 1.1-1.5 times more likely to have an incomplete screen, compared to men, although these estimates were not all significant (Table S3). Age did not have a significant effect on odds of incomplete screening except for the $\mathrm{P} / \mathrm{MC}$ vs OSS cohort (OR: 1.011; 95\% CI [1.001, 1.021]; $P=0.0301)$.

\section{Repeat screenings}

Of the individuals with IBD who had an incomplete screening, the rates of 30- and 90-day repeat screenings were highest for P/MC (18.5\% and 22.2\%, respectively; Table 6). There were no significant differences between agent classes or agents in the odds of returning for a repeat screening colonoscopy, likely due to the small numbers of individuals in this analysis.

Sex was not a significant factor in returning for a repeat screening after an incomplete one, except for the $\mathrm{P} / \mathrm{MC}$ vs OTC cohort, where women had lower odds of returning for a repeat screen within 90 days, compared to men (OR: 
Table 4 Effectiveness outcomes for high-risk individuals, by agent class and the three most frequently used LV agents

\begin{tabular}{|c|c|c|c|c|c|c|}
\hline Agent & $\begin{array}{l}\text { Index } \\
\text { screenings, }^{a} \\
\text { N (\%) }\end{array}$ & $\begin{array}{l}\text { Incomplete } \\
\text { screenings } \\
\% \text { (n) }\end{array}$ & $\begin{array}{l}\text { P/MC odds of } \\
\text { incomplete vs } \\
\text { other agent } \\
(95 \% \mathrm{Cl})\end{array}$ & $\begin{array}{l}\text { 30-day } \\
\text { repeat } \\
\text { screening } \\
\%^{b}(n)\end{array}$ & $\begin{array}{l}\text { 90-day } \\
\text { repeat } \\
\text { screening } \\
\%(n)\end{array}$ & $\begin{array}{l}\text { P/MC odds } \\
\text { of repeat vs } \\
\text { other agent } \\
(95 \% \mathrm{Cl})\end{array}$ \\
\hline$\overline{L V^{c}}$ & $240,749(29.9)$ & $1.07(2,588)$ & $0.74(0.640 .86)^{d}$ & $9.3(24 I)$ & $13.6(35 \mathrm{I})$ & $2.0(1.4,3.0)^{\mathrm{e}}$ \\
\hline HV & $72,638(9.0)$ & $0.98(7 \mid I)$ & $0.82(0.70,0.97)^{f}$ & $9.1(65)$ & $16.6(118)$ & $2.1(1.3,3.3)^{\mathrm{e}}$ \\
\hline OTC & $455,980(56.7)$ & $0.84(3,823)$ & $0.98(0.84,1.15)$ & $12.0(457)$ & $18.6(7 \mid I)$ & $1.6(1.0,2.4)^{f}$ \\
\hline P/MC (LV) & $23,518(2.9)$ & 0.81 (191) & - & $18.3(35)$ & $23.0(44)$ & - \\
\hline OSS (LV) & $134,765(16.8)$ & $1.02(1,371)$ & $0.73(0.63,0.86)^{d}$ & $7.8(107)$ & $11.6(159)$ & $2.6(1.7,4.0)^{\circ}$ \\
\hline PEG+ AA (LV) & 94,784 (II.8) & $1.20(1,136)$ & $0.62(0.53,0.73)^{d}$ & $10.4(118)$ & I5.I (I72) & $1.9(1.2,2.9)^{\mathrm{e}}$ \\
\hline
\end{tabular}

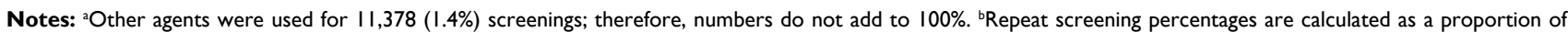
the number of incomplete screenings. ' $D$ ata for the LV class do not include $P / M C$. ${ }^{d} P<0.00 I$, compared to $P / M C$. ${ }^{e} P<0.01$, compared to $P / M C$. $P<0.05$, compared to $P / M C$. Abbreviations: AA, ascorbic acid; HV, high volume; LV, low volume; OSS, oral sulfate solution; OTC, over-the-counter; PEG, polyethylene glycol; P/MC, sodium picosulfate, magnesium oxide, and citric acid.

Table 5 Rates of hospitalizations for high-risk individuals, by agent class and the three most frequently used LV agents

\begin{tabular}{llll}
\hline Agent & $\begin{array}{l}\text { Index } \\
\text { screenings, } \\
\mathbf{N}\end{array}$ & $\begin{array}{l}\text { Hyponatremia } \\
\text { hospitalization } \\
\%(\mathbf{n})\end{array}$ & $\begin{array}{l}\text { Dehydration } \\
\text { hospitalization } \\
\%(\mathbf{n})\end{array}$ \\
\hline LV $^{\mathbf{a}}$ & 240,749 & $0.002(4)$ & $0.002(4)$ \\
HV & 72,638 & 0 & 0 \\
OTC & 455,980 & $0.004(16)$ & $0.008(37)$ \\
P/MC (LV) & 23,518 & 0 & $0.004(1)$ \\
OSS (LV) & 134,765 & $0.001(1)$ & $0.003(4)$ \\
PEG+ AA (LV) & 94,784 & $0.002(2)$ & 0 \\
\hline
\end{tabular}

Note: aData for the LV class do not include P/MC.

Abbreviations: AA, ascorbic acid; HV, high volume; LV, low volume; OSS, oral sulfate solution; OTC, over-the-counter; PEG, polyethylene glycol; P/MC, sodium picosulfate, magnesium oxide, and citric acid.

0.605; 95\% CI [0.403, 0.908]; $P=0.02$; Table S3). Age did not have a significant effect on the odds of returning after an incomplete screen.

\section{Hospitalizations}

There were no hospitalizations due to dehydration or hyponatremia recorded for individuals with IBD who used $\mathrm{P} / \mathrm{MC}$, OSS, or PEG + AA for bowel preparation before the index screening (Table 7). OTC agents were associated with higher rates of hospitalizations than the other bowel preparation agents.

\section{Discussion}

Significantly fewer individuals who used $\mathrm{P} / \mathrm{MC}$ as a bowel preparation agent prior to their colonoscopy had an incomplete screening, indicating that $\mathrm{P} / \mathrm{MC}$ was as efficacious as or more efficacious than other commonly used bowel preparation agents. These differences in rates of incom- plete screenings were significant across all patient groups (average-risk, high-risk, and IBD) and compared with other LV agents, HV agents, and OTC agents. Of those who did have an incomplete screening, more individuals who used $\mathrm{P} / \mathrm{MC}$ for their index screening returned for a repeat screening within the specified period compared to individuals who used other LV agents and those who used HV agents, suggesting better tolerability of $\mathrm{P} / \mathrm{MC}$ for bowel preparation. These differences were significant across all comparisons to prescription preparation agents.

The outcomes in this study may have been affected by how each agent was taken, ie, whether it was consumed as a split dose or day before dose, and the bowel preparation that was used with the repeat screening and the outcomes of the repeat screening.

Reports in the literature indicate that approximately $20 \%$ of all colonoscopies show inadequate bowel preparation. ${ }^{10,13,23}$ Recent studies of single center medical records showed an average rate of inadequate bowel preparation of 9-19.5\%, with the inadequacy varying depending on the bowel preparation agent. ${ }^{24,25}$ However, physicians may decide to perform intra-procedure cleansing to enable better visibility of the colonic mucosa and complete the colonoscopy, rather than risk the individual not returning for a repeat screening after an incomplete colonoscopy. ${ }^{10}$ Therefore, the rates of incomplete screenings measured in this study may reflect this practice and lead to rates of incomplete screenings that are lower than rates of incomplete bowel preparations. Additionally, this study included only colonoscopies performed on an outpatient basis, which comprise the majority of colonoscopies and tend to have lower incomplete rates than those performed as inpatient procedures. ${ }^{26}$ Clinical trials of bowel preparation agents indicate that in approximately $1-5 \%$ of cases, the 
Table 6 Effectiveness outcomes for the IBD subgroup of high-risk individuals, by agent class and the three most frequently used LV agents

\begin{tabular}{|c|c|c|c|c|c|c|}
\hline Agent & $\begin{array}{l}\text { Index } \\
\text { screenings, }^{a} \\
\text { N (\%) }\end{array}$ & $\begin{array}{l}\text { Incomplete } \\
\text { screenings } \\
\% \text { (n) }\end{array}$ & $\begin{array}{l}\text { P/MC odds of } \\
\text { incomplete vs } \\
\text { other agent } \\
(95 \% \mathrm{Cl})\end{array}$ & $\begin{array}{l}\text { 30-day } \\
\text { repeat } \\
\text { screening } \\
\%^{\mathrm{b}}(\mathrm{n})\end{array}$ & $\begin{array}{l}\text { 90-day } \\
\text { repeat } \\
\text { screening } \\
\%(n)\end{array}$ & $\begin{array}{l}\text { P/MC odds } \\
\text { of repeat vs } \\
\text { other agent } \\
(95 \% \mathrm{Cl})\end{array}$ \\
\hline $\mathbf{L V} \mathbf{c}^{\mathrm{c}}$ & $35,879(28.4)$ & $1.35(485)$ & $0.54(0.37,0.80)^{d}$ & $10.3(50)$ & $15.9(77)$ & $2.5(0.84,7.2)$ \\
\hline HV & $9,980(7.9)$ & $1.50(150)$ & $0.48(0.32,0.73)^{d}$ & $9.3(14)$ & $15.3(23)$ & $2.7(0.73,9.9)$ \\
\hline Отс & $74,216(58.9)$ & $1.35(1,000)$ & $0.55(0.37,0.83)^{d}$ & $11.3(113)$ & $19.4(194)$ & $2.3(0.81,6.5)$ \\
\hline P/MC (LV) & $3,630(2.9)$ & $0.74(27)$ & - & $18.5(5)$ & $22.2(6)$ & - \\
\hline OSS (LV) & $18,897(15.0)$ & $1.32(249)$ & $0.57(0.38,0.84)^{d}$ & $9.2(23)$ & $14.5(36)$ & $3.1(0.92,10.3)$ \\
\hline PEG+ AA (LV) & $15,016(11.9)$ & $1.43(215)$ & $0.49(0.33,0.74)^{d}$ & $11.2(24)$ & $16.7(36)$ & $2.8(0.85,9.3)$ \\
\hline
\end{tabular}

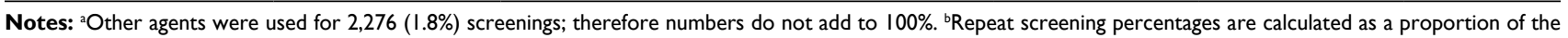
number of incomplete screenings. 'Data for the LV class do not include P/MC. ${ }^{\mathrm{P}}<00.0 \mathrm{I}$, compared to P/MC.

Abbreviations: AA, ascorbic acid; HV, high volume; LV, low volume; OSS, oral sulfate solution; OTC, over-the-counter; PEG, polyethylene glycol; P/MC, sodium picosulfate, magnesium oxide, and citric acid; IBD, inflammatory bowel disease.

Table 7 Rates of hospitalizations for the IBD subgroup of highrisk individuals, by agent class and the 3 most frequently used LV agents

\begin{tabular}{llll}
\hline Agent & $\begin{array}{l}\text { Index } \\
\text { screenings, } \\
\mathbf{N}\end{array}$ & $\begin{array}{l}\text { Hyponatremia } \\
\text { hospitalization } \\
\%(\mathbf{n})\end{array}$ & $\begin{array}{l}\text { Dehydration } \\
\text { hospitalization } \\
\%(\mathbf{n})\end{array}$ \\
\hline LVa & 35,879 & $0.0008(\mathrm{I})$ & 0 \\
HV & 9,980 & 0 & 0 \\
OTC & 74,216 & $0.01(8)$ & $0.03(25)$ \\
P/MC (LV) & 3,630 & 0 & 0 \\
OSS (LV) & 18,897 & 0 & 0 \\
PEG+ AA (LV) & 15,016 & 0 & 0
\end{tabular}

Note: ${ }^{D}$ ata for the LV class do not include P/MC.

Abbreviations: AA, ascorbic acid; HV, high volume; LV, low volume; OSS, oral sulfate solution; OTC, over-the-counter; PEG, polyethylene glycol; P/MC, sodium picosulfate, magnesium oxide, and citric acid; IBD, inflammatory bowel disease.

cecum could not be intubated (incomplete colonoscopy), which is similar to the rates seen in this study. ${ }^{27,28}$

There was no evidence of any new safety issues associated with $\mathrm{P} / \mathrm{MC}$ in real-world use compared to what has been reported in randomized, clinical trials. ${ }^{28}$ The rates of hospitalizations in this study were similar between P/MC and other LV agents. Across all risk groups, OTC agents were associated with the highest rates of hospitalizations due to hyponatremia or dehydration. This may be due to a lack of supplemental electrolytes in OTC preparation agents that are provided in some prescription bowel preparation solutions or variability in fluid intake as part of the bowel preparation procedure. This latter possibility may be related to a lack of standardized instructions for OTC bowel preparation agents. ${ }^{10}$
The high-risk group, as well as the IBD subset of the highrisk group, had higher rates of incomplete screenings than the average-risk group in this study, which may reflect a lower tolerability for more frequent bowel preparations among these patients. In high-risk individuals, including those with IBD, compliance with bowel preparation is particularly critical. ${ }^{29,30}$ However, the tolerability of bowel preparation agents may deter these individuals from returning as needed for screenings. ${ }^{30,31}$ Missed screening colonoscopies can have negative consequences for polyp detection and long-term health. ${ }^{7-9,32}$ Rates of repeat screenings in the high-risk group in this analysis were higher for individuals using $\mathrm{P} / \mathrm{MC}$, suggesting that they were more likely to return for screening than those using other bowel preparation agents.

OTC bowel preparation agents were the most commonly used agents (57\%) for screening colonoscopies in our sample. Another claims study representing just over 500,000 colonoscopies showed slightly lower rates of OTC bowel preparation agent use ( $43 \%$; as defined by the lack of a prescription bowel preparation agent within 30 days before a procedure) than that observed here.$^{18}$ In our study, OTC agents were defined as a lack of prescription for a bowel preparation agent within 90 days before screening. Most of the individuals in this group likely used OTC bowel preparation agents, but it is possible that some used prescription bowel preparation agents that they received as samples from their physicians; this would not have been detected in claims data. Because there is no claims code to indicate an OTC agent, the lack of a prescription was chosen as the best surrogate marker to approximate OTC agent use. 
Limitations of the current study include the use of incomplete screenings as a surrogate for the effectiveness of a bowel preparation agent. This measure may also include individuals who had an incomplete screening due to nonadherence to the bowel preparation instructions; or technical problems related to anatomy, such as a fixed or tortuous colon, or ones secondary to a previous abdominal or pelvic surgery. The study also did not quantify either the impact of an incomplete screening or not returning for a repeat screening on any long-term health outcomes. The time period of 30 or 90 days after the index screening was an arbitrary window used to quantify how many individuals return after an incomplete screening, but these time frames may not have captured all of the individuals who did eventually return. An administrative claims study showed that rates of long-term repeat screening colonoscopies (up to 4 years after index screening) were $12.6 \%$ in commercially insured patients and $19.8 \%$ in Medicare-insured patients. ${ }^{18}$

Additionally, there was no measure of dosing for each agent (ie, how much was actually taken vs how much was prescribed); thus, it remains unknown how much solution is associated with a success or failure of the bowel preparation. Direct measures of patient preferences or tolerability were not acquired in this study, and the rate of repeat screenings after an incomplete one are taken as a surrogate of patient tolerability.

\section{Conclusion}

This study showed that $\mathrm{P} / \mathrm{MC}$ was associated with lower rates of incomplete screening colonoscopy in all patient risk groups and higher rates of a repeat screening within 30 and 90 days of an incomplete screening. These findings suggest that bowel preparation with $\mathrm{P} / \mathrm{MC}$ was more effective in the index screening and less of a deterrent for patients needing repeat screenings. Overall, high-risk individuals had higher rates of incomplete screenings than average-risk individuals, which may necessitate more patient education on the part of the clinician. The safety of $\mathrm{P} / \mathrm{MC}$ was comparable to that of other prescription agents. While OTC agents were used for more than half of the bowel preparations in this study, OTC agents were associated with higher rates of hospitalizations than other agents, which could be caused by the agent itself. Based on the relative effectiveness and safety advantages in average- and high-risk populations, $\mathrm{P} / \mathrm{MC}$ should be considered for all bowel preparations for CRC screening. Standardization and improved clarity of the instructions for OTC bowel preparation agents may help avoid some of the hydration or electrolyte complications associated with these agents.

\section{Acknowledgments}

This study was funded by Ferring Pharmaceuticals Inc., Parsippany, NJ, USA. Medical writing and editorial support was provided by Agnella Izzo Matic, PhD, CMPP, AIM Biomedical and was funded by Ferring Pharmaceuticals Inc.

\section{Author contributions}

All authors contributed toward data analysis, drafting and revising the paper, and agree to be accountable for all aspects of the work.

\section{Disclosure}

Dr Bertiger has served as a consultant and has been a part of the speakers bureau for Ferring Pharmaceuticals Inc. Dr Dahdal and Dr Brogadir are employees of Ferring Pharmaceuticals Inc. Dr Sacks, Mr Cyr, and Mr Sharma are employees of Precision Xtract and provided analysis services to Ferring Pharmaceuticals Inc. The authors report no other conflicts of interest in this work.

\section{References}

1. Rex DK, Johnson DA, Anderson JC, et al. American College of Gastroenterology guidelines for colorectal cancer screening 2009 [corrected]. Am J Gastroenterol. 2009;104(3):739-750.

2. US Preventive Services Task Force; Bibbins-Domingo K, Grossman DC, et al. Screening for colorectal cancer: US Preventive Services Task Force Recommendation Statement. JAMA. 2016;315(23):2564-2575.

3. Itzkowitz SH, Present DH; Crohn's and Colitis Foundation of America Colon Cancer in IBD Study Group. Consensus conference: colorectal cancer screening and surveillance in inflammatory bowel disease. Inflamm Bowel Dis. 2005;11(3):314-321.

4. Brenner H, Chang-Claude J, Seiler CM, Hoffmeister M. Long-term risk of colorectal cancer after negative colonoscopy. J Clin Oncol. 2011;29(28):3761-3767.

5. Chen C, Stock C, Hoffmeister M, Brenner H. Public health impact of colonoscopy use on colorectal cancer mortality in Germany and the United States. Gastrointest Endosc. 2018;87(1):213-221.

6. Murphy CC, Sandler RS, Sanoff HK, Yang YC, Lund JL, Baron JA. Decrease in incidence of colorectal cancer among individuals 50 years or older after recommendations for population-based screening. Clin Gastroenterol Hepatol. 2017;15(6):903-909.

7. Chokshi RV, Hovis CE, Hollander T, Early DS, Wang JS. Prevalence of missed adenomas in patients with inadequate bowel preparation on screening colonoscopy. Gastrointest Endosc. 2012;75(6): $1197-1203$.

8. Harewood GC, Sharma VK, de Garmo P. Impact of colonoscopy preparation quality on detection of suspected colonic neoplasia. Gastrointest Endosc. 2003;58(1):76-79.

9. Lebwohl B, Kastrinos F, Glick M, Rosenbaum AJ, Wang T, Neugut AI. The impact of suboptimal bowel preparation on adenoma miss rates and the factors associated with early repeat colonoscopy. Gastrointest Endosc. 2011;73(6):1207-1214.

10. ASGE Standards of Practice Committee; Saltzman JR, Cash BD, Pasha SF, et al. Bowel preparation before colonoscopy. Gastrointest Endosc. 2015;81(4):781-794.

11. Ko CW, Riffle S, Shapiro JA, et al. Incidence of minor complications and time lost from normal activities after screening or surveillance colonoscopy. Gastrointest Endosc. 2007;65(4):648-656. 
12. Nicholson FB, Korman MG. Acceptance of flexible sigmoidoscopy and colonoscopy for screening and surveillance in colorectal cancer prevention. J Med Screen. 2005;12(2):89-95.

13. Rex DK. Optimal bowel preparation - a practical guide for clinicians. Nat Rev Gastroenterol Hepatol. 2014;11(7):419-425.

14. Holt EW, Yimam KK, Ma H, Shaw RE, Sundberg RA, Verhille MS. Patient tolerability of bowel preparation is associated with polyp detection rate during colonoscopy. J Gastrointestin Liver Dis. 2014;23(2): 135-140.

15. Martel M, Barkun AN, Menard C, Restellini S, Kherad O, Vanasse A. Split-dose preparations are superior to day-before bowel cleansing regimens: a meta-analysis. Gastroenterology. 2015;149(1):79-88.

16. Avalos DJ, Castro FJ, Zuckerman MJ, et al. Bowel preparations administered the morning of colonoscopy provide similar efficacy to a split dose regimen: a meta analysis. J Clin Gastroenterol. Epub 2017 Sep 6.

17. Young LE, Sacks NC, Cyr PL, Sharma A, Dahdal DN. Comparison of claims data on hospitalization rates and repeat procedures in patients receiving a bowel preparation prior to colonoscopy. SAGE Open Med. 2017;5:2050312117727999.

18. Pyenson B, Scammell C, Broulette J. Costs and repeat rates associated with colonoscopy observed in medical claims for commercial and Medicare populations. BMC Health Serv Res. 2014;14:92.

19. Wexner SD, Beck DE, Baron TH. Consensus document on bowel preparation for colonoscopy. Gastrointest Endosc. 2006;63(7): 894-909.

20. Kim HN, Raju GS. Bowel preparation and colonoscopy technique to detect non-polypoid colorectal neoplasms. Gastrointest Endosc Clin N Am. 2010;20(3):437-448.

21. Charlson ME, Pompei P, Ales KL, Mackenzie CR. A new method of classifying prognostic comorbidity in longitudinal studies: development and validation. J Chronic Dis. 1987;40(5):373-383.

22. Quan H, Li B, Couris CM, et al. Updating and validating the Charlson comorbidity index and score for risk adjustment in hospital discharge abstracts using data from 6 countries. Am J Epidemiol. 2011;173(6):676-682.
23. Johnson DA, Barkun AN, Cohen LB, et al. Optimizing adequacy of bowel cleansing for colonoscopy: recommendations from the US multi-society task force on colorectal cancer. Gastroenterology. 2014;147(4):903-924.

24. Sarvepalli S, Garber A, Rizk M, et al. 923 Adjusted comparison of commercial bowel preparations based on inadequacy of bowel preparation in outpatient settings. Gastrointest Endosc. 2018;87(6):AB127.

25. Gu P, Lew D, Ko JZ, et al. Mo1630 - comparing the real-world effectiveness of competing colonoscopy bowel preparations on bowel cleansing and adenoma detection: results of a large prospective trial. Gastroenterology. 2018;154(6):S-775-770.

26. Enns R, Krygier D. The in-patient colonoscopy: a difficult endeavor. Can J Gastroenterol. 2008;22(11):900-902.

27. Bitoun A, Ponchon T, Barthet M, et al. Results of a prospective randomised multicentre controlled trial comparing a new 2-L ascorbic acid plus polyethylene glycol and electrolyte solution vs sodium phosphate solution in patients undergoing elective colonoscopy. Aliment Pharmacol Ther. 2006;24(11-12):1631-1642.

28. Katz PO, Rex DK, Epstein M, et al. A dual-action, low-volume bowel cleanser administered the day before colonoscopy: results from the SEE CLEAR II study. Am J Gastroenterol. 2013;108(3):401-409.

29. Nett A, Velayos F, Mcquaid K. Quality bowel preparation for surveillance colonoscopy in patients with inflammatory bowel disease is a must. Gastrointest Endosc Clin N Am. 2014;24(3):379-392.

30. Restellini S, Kherad O, Bessissow T, et al. Systematic review and metaanalysis of colon cleansing preparations in patients with inflammatory bowel disease. World J Gastroenterol. 2017;23(32):5994-6002.

31. Denters MJ, Schreuder M, Depla AC, et al. Patients' perception of colonoscopy: patients with inflammatory bowel disease and irritable bowel syndrome experience the largest burden. Eur J Gastroenterol Hepatol. 2013;25(8):964-972.

32. Sulz MC, Kröger A, Prakash M, Manser CN, Heinrich H, Misselwitz B. Meta-analysis of the effect of bowel preparation on adenoma detection: early adenomas affected stronger than advanced adenomas. PLoS One. 2017;11(6):e0154149. 


\section{Supplementary materials}

Table SI Point estimates of sex and age covariate effects in multivariate analyses - average-risk group

\begin{tabular}{|c|c|c|c|c|c|c|}
\hline \multirow[t]{2}{*}{ Cohort comparison } & \multicolumn{3}{|c|}{ Sex (female vs male) } & \multicolumn{3}{|c|}{ Age (increase by I year) } \\
\hline & OR & $95 \% \mathrm{Cl}$ & $P$-value & OR & $95 \% \mathrm{Cl}$ & $P$-value \\
\hline \multicolumn{7}{|l|}{ Incomplete } \\
\hline $\mathrm{P} / \mathrm{MC}$ vs LV & $\mathrm{I} .486$ & {$[1.407,1.569]$} & $<0.0001$ & 1.001 & {$[0.999,1.004]$} & 0.2782 \\
\hline $\mathrm{P} / \mathrm{MC}$ vs $\mathrm{HV}$ & 1.502 & {$[1.372,1.644]$} & $<0.0001$ & 0.999 & {$[0.995,1.004]$} & 0.7436 \\
\hline $\mathrm{P} / \mathrm{MC}$ vs OTC & $\mathrm{I} .38 \mathrm{I}$ & {$[1.322,1.442]$} & $<0.0001$ & 1.002 & {$[1,1.004]$} & 0.0817 \\
\hline $\mathrm{P} / \mathrm{MC}$ vs OSS & $\mathrm{I} .483$ & {$[1.378,1.595]$} & $<0.0001$ & 1.004 & {$[1,1.008]$} & 0.0378 \\
\hline $\mathrm{P} / \mathrm{MC}$ vs $\mathrm{PEG}+\mathrm{AA}$ & 1.501 & {$[1.387,1.625]$} & $<0.0001$ & 0.997 & {$[0.993,1.001]$} & 0.0947 \\
\hline \multicolumn{7}{|c|}{ Repeat after incomplete } \\
\hline P/MC vs LV & 0.839 & {$[0.7,1.006]$} & 0.0579 & 0.99 & {$[0.982,0.999]$} & 0.0354 \\
\hline $\mathrm{P} / \mathrm{MC}$ vs HV & 0.915 & {$[0.696,1.203]$} & 0.5258 & 0.986 & {$[0.974,0.998]$} & 0.0255 \\
\hline P/MC vs OTC & 0.788 & {$[0.697,0.89]$} & 0.0001 & 0.991 & {$[0.986,0.997]$} & 0.0016 \\
\hline $\mathrm{P} / \mathrm{MC}$ vs OSS & 0.861 & {$[0.66,1.125]$} & 0.2724 & 0.989 & {$[0.976,1.002]$} & 0.1102 \\
\hline $\mathrm{P} / \mathrm{MC}$ vs $\mathrm{PEG}+\mathrm{AA}$ & 0.87 & {$[0.684,1.106]$} & 0.2544 & 0.987 & {$[0.976,0.998]$} & 0.021 \\
\hline
\end{tabular}

Abbreviations: AA, ascorbic acid; HV, high volume; LV, low volume; OSS, oral sulfate solution; OTC, over-the-counter; PEG, polyethylene glycol; P/MC, sodium picosulfate, magnesium oxide, and citric acid.

Table S2 Point estimates of sex and age covariate effects in multivariate analyses - high-risk group

\begin{tabular}{|c|c|c|c|c|c|c|}
\hline \multirow[t]{2}{*}{ Cohort comparison } & \multicolumn{3}{|c|}{ Sex (female vs male) } & \multicolumn{3}{|c|}{ Age (increase by I year) } \\
\hline & OR & $95 \% \mathrm{Cl}$ & $P$-value & OR & $95 \% \mathrm{Cl}$ & $P$-value \\
\hline \multicolumn{7}{|l|}{ Incomplete } \\
\hline $\mathrm{P} / \mathrm{MC}$ vs LV & 1.427 & {$[1.319,1.545]$} & $<0.0001$ & 0.997 & {$[0.993,1.001]$} & $0.147 \mid$ \\
\hline $\mathrm{P} / \mathrm{MC}$ vs HV & 1.369 & {$[1.193,1.572]$} & $<0.0001$ & I & {$[0.993,1.006]$} & 0.9509 \\
\hline P/MC vs OTC & 1.381 & {$[1.293,1.474]$} & $<0.0001$ & 0.994 & {$[0.991,0.997]$} & $<0.0001$ \\
\hline $\mathrm{P} / \mathrm{MC}$ vs OSS & 1.387 & {$[1.244,1.546]$} & $<0.0001$ & 1.004 & {$[0.998,1.009]$} & 0.1724 \\
\hline $\mathrm{P} / \mathrm{MC}$ vs $\mathrm{PEG}+\mathrm{AA}$ & 1.526 & {$[1.355,1.718]$} & $<0.0001$ & 0.993 & {$[0.987,0.998]$} & 0.0096 \\
\hline \multicolumn{7}{|c|}{ Repeat after incomplete } \\
\hline P/MC vs LV & 0.995 & {$[0.762,1.3]$} & 0.9717 & 0.989 & {$[0.976,1.003]$} & 0.1173 \\
\hline $\mathrm{P} / \mathrm{MC}$ vs HV & 1.107 & {$[0.7,1.75]$} & 0.6646 & 0.973 & {$[0.953,0.994]$} & 0.0122 \\
\hline $\mathrm{P} / \mathrm{MC}$ vs OTC & 0.878 & {$[0.719,1.07 I]$} & 0.1997 & 0.997 & {$[0.988,1.006]$} & 0.5593 \\
\hline $\mathrm{P} / \mathrm{MC}$ vs OSS & 1.215 & {$[0.816,1.809]$} & 0.3376 & 0.995 & {$[0.974,1.015]$} & 0.6015 \\
\hline $\mathrm{P} / \mathrm{MC}$ vs $\mathrm{PEG}+\mathrm{AA}$ & 0.84 & {$[0.575,1.226]$} & 0.365 & 0.983 & {$[0.965,1.002]$} & 0.0762 \\
\hline
\end{tabular}

Abbreviations: AA, ascorbic acid; HV, high volume; LV, low volume; OSS, oral sulfate solution; OTC, over-the-counter; PEG, polyethylene glycol; P/MC, sodium picosulfate, magnesium oxide, and citric acid. 
Table S3 Point estimates of sex and age covariate effects in multivariate analyses - IBD subgroup

\begin{tabular}{|c|c|c|c|c|c|c|}
\hline \multirow[t]{2}{*}{ Cohort comparison } & \multicolumn{3}{|c|}{ Sex (female vs male) } & \multicolumn{3}{|c|}{ Age (increase by I year) } \\
\hline & $\overline{\text { OR }}$ & $95 \% \mathrm{Cl}$ & $P$-value & $\overline{\text { OR }}$ & $95 \% \mathrm{Cl}$ & $P$-value \\
\hline \multicolumn{7}{|l|}{ Incomplete } \\
\hline P/MC vs LV & 1.203 & {$[1.003,1.444]$} & 0.0466 & 1.005 & {$[0.998,1.012]$} & 0.1571 \\
\hline $\mathrm{P} / \mathrm{MC}$ vs HV & 1.301 & {$[0.954,1.774]$} & 0.0966 & 1.001 & {$[0.989,1.012]$} & 0.9117 \\
\hline $\mathrm{P} / \mathrm{MC}$ vs OTC & 1.317 & {$[1.156,1.5]$} & $<0.0001$ & 1.004 & {$[0.999,1.008]$} & 0.1101 \\
\hline P/MC vs OSS & 1.128 & {$[0.88 \mathrm{I}, 1.445]$} & 0.3407 & 1.011 & {$[1.001,1.021]$} & 0.0301 \\
\hline $\mathrm{P} / \mathrm{MC}$ vs $\mathrm{PEG}+\mathrm{AA}$ & 1.464 & {$[1.115,1.922]$} & 0.0061 & 0.998 & {$[0.988,1.008]$} & 0.718 \\
\hline \multicolumn{7}{|c|}{ Repeat after incomplete } \\
\hline P/MC vs LV & 0.817 & {$[0.437,1.528]$} & 0.5274 & 1 & {$[0.977,1.024]$} & 0.9869 \\
\hline $\mathrm{P} / \mathrm{MC}$ vs HV & 2.491 & {$[0.674,9.213]$} & 0.1713 & 0.991 & {$[0.952,1.032]$} & 0.6587 \\
\hline $\mathrm{P} / \mathrm{MC}$ vs OTC & 0.605 & {$[0.403,0.908]$} & 0.0154 & 1.001 & {$[0.986,1.016]$} & 0.9406 \\
\hline P/MC vs OSS & 1.402 & {$[0.522,3.766]$} & 0.5026 & 1.009 & {$[0.972,1.047]$} & 0.6515 \\
\hline $\mathrm{P} / \mathrm{MC}$ vs $\mathrm{PEG}+\mathrm{AA}$ & 0.52 & {$[0.21,1.291]$} & 0.1588 & 1.009 & {$[0.975,1.045]$} & 0.5957 \\
\hline
\end{tabular}

Abbreviations: AA, ascorbic acid; HV, high volume; LV, low volume; OSS, oral sulfate solution; OTC, over-the-counter; PEG, polyethylene glycol; P/MC, sodium picosulfate, magnesium oxide, and citric acid; IBD, inflammatory bowel disease.

Clinical and Experimental Gastroenterology

\section{Publish your work in this journal}

Clinical and Experimental Gastroenterology is an international, peerreviewed, open access, online journal publishing original research, reports, editorials, reviews and commentaries on all aspects of gastroenterology in the clinic and laboratory. This journal is included on PubMed. The manuscript management system is completely online

\section{Dovepress}

and includes a very quick and fair peer-review system, which is all easy to use. Visit http://www.dovepress.com/testimonials.php to read real quotes from published authors.

Submit your manuscript here: https://www.dovepress.com/clinical-and-experimental-gastroenterology-journal 